\title{
HYDRAULIC FRACTURING PROPAGATION MECHANISM DURING SHALE GAS RESERVOIR STIMULATION THROUGH HORIZONTAL WELL
}

\author{
Tian-hui Ma, Quan-ao Wu, Chun-an Tang, Hong-yuan Liu
}

Original scientific paper

The fracture pattern of rock mass in shale gas reservoirs is one of the main factors affecting the efficiency of hydraulic fracturing. In this paper, physical experiments and numerical modelling were conducted to systematically investigate the effect of the in-situ stress and perforation angle on the hydraulic fracture initiation pressure and location, fracture propagation, and fracture pattern in a horizontal well drilled by Sinopec Corp. in Luojia area of Shengli Oilfield. A total of six different in-situ stress combinations and eight different perforation angles were considered for the stratified rock mass during the hydraulic fracturing. A summary of the fracture initiations and propagation, and the final fracture patterns induced by the hydraulic fracturing in the stratified rock masses reveals that, for the stratified rock masses with the same perforation angle, the larger the in-situ stress ratio (i.e. lower maximum horizontal principal stress when the vertical stress remains constant) is, the lower hydraulic pressure is required for hydraulic fracturing initiation and propagation. Moreover, it is found that, for the stratified rock mass under the same stress ratio, the hydraulic fracturing pressure in the case with a perforation angle of $30^{\circ}$ is higher than that in all other cases. Furthermore, it is noted that the effect of the stratification on the hydraulic fracturing becomes weaker with the in-situ stress ratio increasing. It is finally concluded that the results from this study can provide important theoretical guidance for improving the hydraulic fracturing design in order to ensure the effective shale gas reservoir stimulations.

Keywords: fracture pattern; horizontal well; hydraulic fracturing; in-situ stress; perforation angle

\section{Mehanizam za propagaciju hidrauličkog frakturiranja tijekom stimuliranja naslaga naftnih škriljaca kroz horizontalnu bušotinu}

Način razlamanja stijenske mase u naslagama naftnih škriljaca jedan je od glavnih čimbenika koji djeluju na učinkovitost hidrauličkog frakturiranja (frakiranja). U ovom su radu provedena fizikalna ispitivanja i numeričko modeliranje u svrhu sustavnog ispitivanja učinka in-situ (podzemnog) naprezanja i kuta bušenja na stvaranje tlaka zbog hidrauličkog frakturiranja, širenje razlamanja i način razlamanja u horizontalnoj bušotini naftnog nalazišta Shengli u Luojia pokrajini, u izvođenju Sinopec Corp. Ukupno je razmatrano šest različitih in-situ kombinacija naprezanja i osam različitih kutova bušenja slojevite stijenske mase tijekom hidrauličkog frakturiranja. Sažetak nastanka i širenja pukotine te završni oblici pukotina nastalih hidrauličkim frakturiranjem u slojevitim stijenskim masama otkrivaju da kod stratificiranih stijena s istim kutom bušenja, što je veći in-situ omjer naprezanja (t.j. niže maksimalno horizontalno osnovno naprezanje pri konstantnim vertikalnim naprezanjem), potreban je niži hidraulički tlak za poticanje i širenje hidrauličkog frakturiranja. Štoviše, ustanovljeno je da je kod stratificirane stijenske mase pri istom omjeru naprezanja, tlak hidrauličkog frakturiranja, u slučaju kad je kut bušenja $30^{\circ}$, veći nego u svim drugim slučajevima. Nadalje, zapaženo je da učinak stratifikacije na hidrauličko frakturiranje postaje slabiji s porastom in-situ omjera naprezanja. Konačno je zaključeno da rezultati ove analize mogu biti važan teorijski pokazatelj u poboljšanju oblikovanja hidrauličkog frakturiranja kako bi se osiguralo učinkovito stimuliranje naslaga naftnih škriljaca.

Ključne riječi: hidrauličko frakturiranje; horizontalna bušotina; in-situ naprezanje; kut bušenja; način razlamanja

\section{Introduction}

Shale gas refers to the natural gas accumulated in organic-rich, dark-coloured or high-carbon shale mainly in the form of adsorbed or free gas [1]. Shale gas has a very wide application prospect, which is extremely important in the countries dominated by this type of energy resource. Shale gas is widely distributed worldwide, with a total storage volume of $4,56 \times 10^{14} \mathrm{~m}^{3}$, which is half of the petroleum gas resource in the world $[2,3]$.

As the shale gas reservoir is usually of low porosity and low permeability, only very small number of natural reservoirs can be directly used for production. In fact, most shale gas wells need to be subjected to a series of stimulations before the desired yield can be achieved [4] Hydraulic fracturing is the most effective shale gas reservoir stimulation method and, correspondingly, the hydraulic fracturing theory and practice have been further advanced.

The hydraulic fracturing technique was first successfully applied in Kansas State, USA, in 1947. The classical hydraulic fracturing method was then proposed by Hybbert and Willis in 1957 [4, 5]. With development over 60 years, the hydraulic fracturing technique has now been widely applied in underground engineering, such as the exploitation of petroleum, geotherm and coalbed methane, disposal of nuclear waste and measurement of geostresses. Some research achievements have been made in terms of both theory and practice. Hydraulic fracturing has become an important technical means to improve the well output and recovery efficiency in low-permeability reservoirs during the exploitation of oil and gas fields [6].

Especially in recent years, driven by the horizontal well staged hydraulic fracturing, great success has been achieved for unconventional natural gas exploitation in extremely low-permeability shale reservoirs in the Granada area of the U. S. The yielded shale gas reached $1720,0 \times 10^{8} \mathrm{~m}^{3}$ in the U.S. in 2011 , which was much more than the total natural gas produced in China in $2011\left(1025,3 \times 10^{8} \mathrm{~m}^{3}\right)[7]$.

The pattern of hydraulic fracture is one of the main factors affecting the efficiency of hydraulic fracturing: for cost-effective fracturing, the fractures should propagate in the reservoir bed as far as possible and meanwhile the fracture propagation through pervious layer or lowpressure permeable layer should be prevented [8]. In traditional hydraulic fracturing theory, the hydraulic fractures far away from the well are considered as the symmetrical double-wing cracks propagating perpendicularly to the direction of minimum principal insitu stress. During recent years, many researchers have realized that hydraulic fractures can propagate in much 


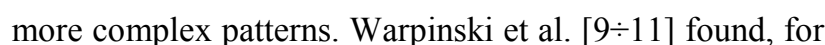
the first time, that the main fracture and complex branch fractures could propagate simultaneously and proposed the concept of fracture extension zone. With physical model tests, Blanton [12,13] and Chen et al. [14:17] found that three cases were possible after the hydraulic fractures intersected with natural fractures, i.e., the hydraulic fractures might penetrate, turn or penetrate and turn at the same time. Mahrer [18] suggested that the natural fractures and hydraulic fractures would together form a fracture network. Later, Beugelsdijk [19] verified the existence of the fracture network by laboratory tests. Fisher et al. [20, 21] and Mawell et al. [22, 23] confirmed the existence of the fracture network in the field of shale gas reservoirs by microseismic monitoring. In sum, hydraulic fractures are the key to the successful modification of shale gas reservoir beds [24].

From the previous researches reviewed above, it can be seen that, till this moment, the primary evaluation on the fracturing efficiency and the fracture propagation law are based on the change of oil and gas yield after fracturing and the experiences in hydraulic fracturing. Moreover, although some achievements have also been made in the numerical simulation of fracture propagation during hydraulic fracturing, these numerical simulations mainly focus on the studies of the static parameters related to hydraulic fracturing such as the fracture pattern and the dimension (length, width and height) of the fractures. Few studies have been conducted on the dynamic parameters of hydraulic fractures, such as the dynamic propagation direction, path and range. Especially, as commented by Sun et al. [6], numerical simulations are seldom reported to investigate the interaction between the hydraulic fractures and the oriented cracks created by perforation and slotting.

In view of the non-systematic and incomplete knowledge on the formation mechanism of fracture network in shale gas reservoir beds, this study took a well drilled by Sinopec Corp. in Luojia area of Shengli Oilfield as an example to conduct a systematic study on the effect of the deviatoric stress and perforation angle on the hydraulic fracture initiation pressure, fracture initiation location, fracture propagation and fracture pattern during hydraulic fracturing [25]. This study can provide important theoretical guidance for improving the reliability of hydraulic fracturing design in stimulating shale gas reservoirs.

\section{Computation principle and physical test for obtaining the parameters of hydraulic fractures \\ 2.1 Introduction of computation principle for modelling hydraulic fractures}

Natural rock masses are discontinuous, inhomogeneous, inelastic and anisotropic media, which are time-dependent, path-dependent and environmentdependent. Although many theoretical formulas have been derived according to classical mechanics, they are not applicable to the complex engineering rock masses [25]. In many practical engineering projects, rock mass deformation, failure and strength calculated by these idealized formulas are far from the true values. So far, the knowledge on the irregularity, complexity and nonlinearity of the physical and mechanical properties of the rock mass is still incomplete and relevant issues are yet to be solved. Consequently, many rock mechanics problems cannot be explained and analysed quantitatively or even qualitatively.

Statistics theory has been playing a significant role in the studies on the strength of heterogeneous materials at mesoscopic level. As the macroscopic manifestation of mesoscopic statistical strength, the deformation and failure processes of geological materials can be well explained. Hence, the statistics theory is considered as a rigorous and promising method of studying heterogeneous materials. The strength obtained from the viewpoint of mesoscopic statistics of the heterogeneous material reflects inevitably the overall strength of the heterogeneous material. In this paper, the seepage module of the realistic failure process analysis (RFPA-Flow) is adopted for numerical simulation. The rock homogeneity is realized by assigning the mechanical parameters (elastic modulus, Poisson's ratio, compressive strength, etc.) of the rock according to the Weibull distribution in Eq. (1).

$$
\phi(\alpha)=\frac{m}{\alpha_{0}}\left(\frac{\alpha}{\alpha_{0}}\right)^{m-1} \mathrm{e}^{-\left(\frac{\alpha}{\alpha_{0}}\right)^{m}}
$$

where $\alpha$ is the mechanical parameter of meso-elements of a medium (rock); $\alpha_{0}$ is the statistical average of mesoscopic mechanical properties; $m$ is the heterogeneity index, and the larger the homogeneous index $m$, the higher the homogeneous degree is; and $\phi(\alpha)$ is the probability density function of $\alpha$.

The fluid flow in the medium (rock) of a RFPA-Flow model satisfies the Biot's consolidation theory. The mesoscopic element of the rock medium is assumed to be an elastic-brittle material with a certain residual strength. Its mechanical behaviours during the loading and unloading processes conform to the elastic damage theory. The maximum tensile strength criterion and the MohrCoulomb strength criterion are employed as the failure criteria for the elements under tensile and compressive loading conditions, respectively. In the elastic state, the relationship between the stress and permeability coefficient of the material can be described by a negative exponential function in Eq. (2).

$K_{f}=K_{0} e^{-b \sigma}$

where $K_{0}$ is the initial permeability coefficient; $\sigma$ is the normal stress; and $b$ is the coupling parameter.

Under the same loading condition, the seepage behavior in rock mass with growing fractures is different from that with pre-existing fractures. Hence, during the damage process of fractured rock mass, the permeability of the rock mass keeps changing. RFPA-Flow can consider not only the propagation of pre-existing fractures and the initiation of new fractures, but also the seepagestress-damage coupling effect during the propagations of both two types of fractures. In this way, the numerical simulation can reproduce the coupling behaviour of fluid 
and rock during the rock damage and failure process in hydraulic fracturing and the modeling results are more realistic and reasonable, compared with those obtained using other fluid and solid coupling software.

The fundamental equations for modelling the fluidsolid coupling during the rock damage and failure process in hydraulic fracturing using RFPA-Flow are denoted in Eqs. (3) $\div(6)$, which include the equilibrium equation in Eq. (3):

$$
\frac{\partial \sigma_{i j}}{\partial x_{i j}}+\rho X_{j}=0, i, j=1,2,3 .
$$

The geometric equation in Eq. (4):

$\varepsilon_{i j}=\frac{1}{2}\left(u_{i, j}+u_{j, i}\right), \quad \varepsilon_{v}=\varepsilon_{11}+\varepsilon_{22}+\varepsilon_{33}$

The constitutive equation in Eq. 5:

$\sigma_{i j}^{\prime}=\sigma_{i j}-\alpha p \delta_{i j}=\lambda \delta_{i j} \varepsilon_{v}+2 G \varepsilon_{i j}$

The seepage equation in Eq. 6:

$K \nabla^{2} p=\frac{1}{Q} \frac{\partial p}{\partial t}-\alpha \frac{\partial \varepsilon_{v}}{\partial t}$

where $\rho$ is the density; $\sigma_{i j}$ is the summation of normal stresses; $\varepsilon_{v}, \varepsilon_{i i}$ are the volumetric strain and normal strain, respectively; $\delta$ is the Kronecker constant; $Q$ is the Biot constant; $G$ and $\lambda$ are the shear modulus and the Lame constant, respectively; and $\nabla^{2}$ is the Laplace operator.

The change of the permeability coefficient during the seepage-stress coupling is denoted in Eq. (7):

$k(\sigma, p)=\xi k_{0} \mathrm{e}^{-\beta\left(\frac{\sigma_{i i}}{3}-\alpha p\right)}$,

where $k_{0}$ is the permeability coefficient, $p$ is the pore water pressure, $\xi$ is the mutation coefficient of permeability coefficient, $\alpha$ is the coefficient of pore water pressure, and $\beta$ is the coupling coefficient (stress sensitivity factor) which is determined by experiments and varies under different stress states.

Furthermore, a large amount of experimental results indicated that the permeability coefficient is not only a function of stress, but also varies remarkably during the damage and failure evolution process induced by stresses. In RFPA-Flow, the variation of the permeability coefficient beyond the elastic behaviour of the rock is associated with the damage and failure process of the rock under various loading conditions. When the stress or strain state of an element satisfies a prescribed damage threshold, the element damage occurs. The elastic modulus of the damaged element is denoted by Eq. (8):

$E=(1-D) E_{0}$,

where $D$ is the damage variable; $E$ and $E_{0}$ are the elastic modulus of the damaged and non-damaged elements. The variation of the damage variable $D$ depends on the failure type and the strain state of the element. Let us take an element under the uniaxial tensile stress as an example. When the element stress reaches the damage threshold, i.e. the tensile strength $f_{t}$ in Eq. (9) in this case,

$\sigma_{3} \leq-f_{t}$

the damage variable can be denoted using Eq. (10)

$D=\left\{\begin{array}{c}0, \varepsilon_{t 0} \leq \varepsilon ; \\ 1-\frac{f_{t r}}{E_{0} \varepsilon}, \varepsilon_{t u} \leq \varepsilon \leq \varepsilon_{0} ; \\ 1, \varepsilon \leq \varepsilon_{t u} .\end{array}\right.$

where $f_{t r}$ is the residual strength; and $\varepsilon_{t 0}$ and $\varepsilon_{t u}$ are the maximum tensile strain and ultimate tensile strain, respectively.

The corresponding permeability coefficient of the element follows Eq. (11):

$K=\left\{\begin{array}{c}K_{0} e^{-\beta\left(\sigma_{3}-\alpha p\right)}, D=0 \\ \xi K_{0} e^{-\beta\left(\sigma_{3}-\alpha p\right)}, 0<D<1 \\ \xi^{\prime} K_{0} e^{-\beta\left(\sigma_{3}-p\right)}, D=1\end{array}\right.$

Similarly, the equations denoting the variations of the damage variable and the permeability coefficient of the elements under uniaxial compression can be obtained during the element damage and failure process, as depicted in Fig. 1. Moreover, these equations can be extrapolated to denote the variations of the damage variable and the permeability coefficient of the elements under multi-axial loading conditions.

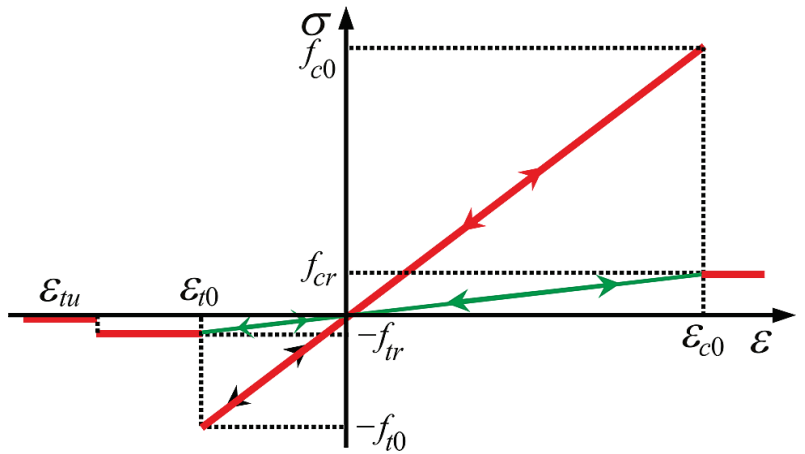

Figure 1 Constitutive model of mesoscopic element under uniaxial compression and tension

\subsection{Criterion for hydraulic fracture propagation}

The propagation and failure criterion is necessary in order to study extension of hydraulic fractures. The elastic energy dissipated for per unit of newly created fracture surface area is defined as the energy release rate for fracture propagation and denoted by $G$. The critical energy release rate is represented by $G_{c}$, which is a constant independent of external loading condition and geometric shape of fractures. For a system containing a single fracture with the fracture length of $a$, the fracture starts to propagate when $G=G_{c}$ and $\mathrm{d} G / \mathrm{d} a>0$. 
Table 1 Testing results on the air permeability and fluid permeability of the propped fractures

\begin{tabular}{|c|c|c|c|c|c|c|}
\hline No. & $\begin{array}{l}\text { Length } \\
\left(10^{-2} \mathrm{~m}\right)\end{array}$ & $\begin{array}{c}\text { Sectional area } \\
\left(10^{-4} \mathrm{~m}^{2}\right)\end{array}$ & $\begin{array}{c}\text { Porosity } \\
(\%)\end{array}$ & $\begin{array}{c}\text { Confining pressure } \\
\left(10^{6} \mathrm{~Pa}\right)\end{array}$ & $\begin{array}{l}\text { Gas permeability } \\
(\mathrm{m} / \mathrm{d})\end{array}$ & $\begin{array}{c}\text { Artificial fracture retention } \\
\text { fluid permeability }(\mathrm{m} / \mathrm{d})\end{array}$ \\
\hline \multirow{8}{*}{2} & \multirow{8}{*}{5,06} & \multirow{8}{*}{4,745190} & \multirow{8}{*}{4,54} & 3 & 0,187300 & 6,835531 \\
\hline & & & & 5 & - & 3,417766 \\
\hline & & & & 10 & - & 0,746739 \\
\hline & & & & 15 & - & 0,165215 \\
\hline & & & & 20 & - & 0,047063 \\
\hline & & & & 25 & - & 0,023856 \\
\hline & & & & 30 & - & 0,018089 \\
\hline & & & & 35 & - & 0,017518 \\
\hline \multirow{8}{*}{5} & \multirow{8}{*}{4,12} & \multirow{8}{*}{4,807170} & \multirow{8}{*}{3,5} & 3 & 0,901725 & 79,356807 \\
\hline & & & & 5 & 0,389048 & 27,469664 \\
\hline & & & & 10 & 0,201337 & 4,709085 \\
\hline & & & & 15 & 0,066633 & 1,414279 \\
\hline & & & & 20 & 0,035272 & 0,532993 \\
\hline & & & & 25 & 0,021305 & 0,222495 \\
\hline & & & & 30 & 0,006739 & 0,118870 \\
\hline & & & & 35 & 0,004738 & 0,062285 \\
\hline \multirow{8}{*}{7} & \multirow{8}{*}{3,88} & \multirow{8}{*}{4,838307} & \multirow{8}{*}{2,11} & 3 & 0,005100 & 3,238241 \\
\hline & & & & 5 & - & 2,267683 \\
\hline & & & & 10 & - & 0,283911 \\
\hline & & & & 15 & - & 0,130231 \\
\hline & & & & 20 & - & 0,066217 \\
\hline & & & & 25 & - & 0,058815 \\
\hline & & & & 30 & - & 0,045093 \\
\hline & & & & 35 & - & 0,036302 \\
\hline \multirow{8}{*}{8} & \multirow{8}{*}{3,808} & \multirow{8}{*}{4,861728} & \multirow{8}{*}{2,62} & 3 & 0,010081 & 150,305880 \\
\hline & & & & 5 & 0,002691 & 95,649196 \\
\hline & & & & 10 & 0,001607 & 41,486263 \\
\hline & & & & 15 & 0,000977 & 13,054344 \\
\hline & & & & 20 & 0,000156 & 6,943800 \\
\hline & & & & 25 & 0,000126 & 3,231273 \\
\hline & & & & 30 & 0,000104 & 1,773688 \\
\hline & & & & 35 & 0,000083 & 0,206621 \\
\hline \multirow{8}{*}{9} & \multirow{8}{*}{4,592} & \multirow{8}{*}{4,799399} & \multirow{8}{*}{2,48} & 3 & 0,006900 & 4,622157 \\
\hline & & & & 5 & - & 1,854237 \\
\hline & & & & 10 & - & 0,512747 \\
\hline & & & & 15 & - & 0,204879 \\
\hline & & & & 20 & - & 0,074284 \\
\hline & & & & 25 & - & 0,040576 \\
\hline & & & & 30 & - & 0,022197 \\
\hline & & & & 35 & - & 0,013629 \\
\hline \multirow{8}{*}{12} & & & & 3 & 0,055036 & 10,955489 \\
\hline & & & & 5 & 0,021160 & 5,638855 \\
\hline & & & & 10 & 0,011176 & 1,567914 \\
\hline & & & & 15 & 0,003916 & 0,595304 \\
\hline & 3,334 & 4,830513 & 3,76 & 20 & 0,002219 & 0,056932 \\
\hline & & & & 25 & 0,001701 & 0,050568 \\
\hline & & & & 30 & 0,000497 & 0,038770 \\
\hline & & & & 35 & 0,000395 & 0,031212 \\
\hline
\end{tabular}

Therefore, $G$ and $\mathrm{d} G / \mathrm{d} a$ need to be calculated accurately. For a system containing multiple fractures, the energy release rate at the $i^{\text {th }}$ crack tip can be obtained according to Eq. (12) by the finite element method.

$G_{i}=-\frac{\partial \prod}{\partial \alpha_{i}}=-\frac{1}{2} u^{\mathrm{T}} \frac{\partial K}{\partial \alpha_{i}} u+u^{\mathrm{T}} \frac{\partial f}{\partial \alpha_{i}}$.

When $i \neq j$,

$$
\begin{aligned}
& \frac{\partial G_{i}}{\partial \alpha_{j}}=-u^{\mathrm{T}} \frac{\partial K}{\partial \alpha_{i}} K^{-1}\left[\frac{\partial f}{\partial \alpha_{i}}-\frac{\partial K}{\partial \alpha_{j}} u\right]+ \\
& +\left[\frac{\partial f}{\partial \alpha_{j}}-\frac{\partial K}{\partial \alpha_{j}} u\right] K^{-1^{\mathrm{T}}} \frac{\partial f}{\partial \alpha_{i}} .
\end{aligned}
$$

When $i=j$, 


$$
\begin{aligned}
& \frac{\partial G_{i}}{\partial \alpha_{i}}=-u^{\mathrm{T}} \frac{\partial K}{\partial \alpha_{i}} K^{-1}\left[\frac{\partial f}{\partial \alpha_{j}}-\frac{\partial K}{\partial \alpha_{j}} u\right]-\frac{1}{2} u^{\mathrm{T}} \frac{\partial^{2} K}{\partial \alpha_{i}^{2}} u+ \\
& +\left[\frac{\partial f}{\alpha \alpha_{i}}-\frac{\partial K}{\partial \alpha_{i}} u\right] K^{-1^{\mathrm{T}}} \frac{\partial f}{\partial \alpha_{i}}+u^{\mathrm{T}} \frac{\partial^{2} f}{\partial \alpha^{2}} .
\end{aligned}
$$

where $K$ is the stiffness matrix of the structure, $f$ is the loading vector and $u$ is the displacement vector.

\begin{tabular}{|c|c|c|c|c|c|c|c|c|c|}
\hline Well No & Lithology & $\begin{array}{l}\text { Core } \\
\text { No. }\end{array}$ & $\begin{array}{l}\text { Depth } \\
\text { (m) }\end{array}$ & $\begin{array}{c}\text { Specimen } \\
\text { No. }\end{array}$ & $\begin{array}{l}\text { Coring } \\
\text { position }\end{array}$ & $\begin{array}{c}\text { Geostress } \\
\left(10^{6} \mathrm{~Pa}\right)\end{array}$ & $\begin{array}{l}\text { Horizontal } \\
\text { maximum } \\
\text { geostress } \\
\left(10^{6} \mathrm{~Pa}\right)\end{array}$ & $\begin{array}{c}\text { Horizontal } \\
\text { minimum geostress } \\
\left(10^{6} \mathrm{~Pa}\right)\end{array}$ & $\begin{array}{l}\text { Vertical } \\
\text { geostress } \\
\left(10^{6} \mathrm{~Pa}\right)\end{array}$ \\
\hline \multirow{7}{*}{$\begin{array}{l}\text { Well } 69 \\
\text { of Luojia } \\
\text { area }\end{array}$} & \multirow{7}{*}{ Shale } & \multirow{4}{*}{$18 \frac{13}{31}$} & \multirow{4}{*}{$3050,2 \div 3052,2$} & 1 & $\begin{array}{c}\text { Vertical } \\
\text { direction }\end{array}$ & 60,96 & \multirow{4}{*}{55,52} & \multirow{4}{*}{47,64} & \multirow{4}{*}{61,00} \\
\hline & & & & 2 & $0^{\circ}$ & 53,90 & & & \\
\hline & & & & 3 & $45^{\circ}$ & 48,40 & & & \\
\hline & & & & 4 & $90^{\circ}$ & 49,26 & & & \\
\hline & & \multirow{3}{*}{$18 \frac{13}{31}$} & \multirow{3}{*}{$3048,2 \div 3050,2$} & 5 & $0^{\circ}$ & 52,27 & \multirow{3}{*}{55,48} & \multirow{3}{*}{47,56} & \multirow{3}{*}{60,23} \\
\hline & & & & 6 & $45^{\circ}$ & 47,66 & & & \\
\hline & & & & 7 & $90^{\circ}$ & 50,80 & & & \\
\hline
\end{tabular}

Table 2 Testing results for Kaiser effects of the recovered rock core under confining stresses

\begin{tabular}{|c|c|c|c|c|c|c|c|c|c|}
\hline $\begin{array}{l}\text { Well } \\
\text { No. }\end{array}$ & Lithology & $\begin{array}{l}\text { Core } \\
\text { No. }\end{array}$ & $\begin{array}{l}\text { Depth } \\
\text { (m) }\end{array}$ & $\begin{array}{c}\text { Specimen } \\
\text { No. }\end{array}$ & $\begin{array}{l}\text { Diameter } \\
D\left(10^{-3} \mathrm{~m}\right)\end{array}$ & $\begin{array}{l}\text { Height } H \\
\left(10^{-3} \mathrm{~m}\right)\end{array}$ & $\begin{array}{c}\text { Uniaxial compressive } \\
\text { strength } \\
\sigma_{1}\left(10^{6} \mathrm{~Pa}\right) \\
\end{array}$ & $\begin{array}{c}\text { Elastic } \\
\text { Modulus } E \\
\left(10^{10} \mathrm{~Pa}\right)\end{array}$ & $\begin{array}{c}\text { Poisson's } \\
\text { ratio } \\
v\end{array}$ \\
\hline \multirow{5}{*}{$\begin{array}{c}\text { Well } \\
69 \text { of } \\
\text { Luojia } \\
\text { area }\end{array}$} & \multirow{5}{*}{ Shale } & \multirow{2}{*}{$18 \frac{4}{31}$} & \multirow{2}{*}{$3048,2 \div 3050,2$} & A3 & 24,96 & 48,56 & 28,288 & 1,539 & 0,156 \\
\hline & & & & A4 & 24,54 & 49,20 & 72,010 & 2,576 & 0,125 \\
\hline & & \multirow{2}{*}{$18 \frac{4}{31}$} & \multirow{2}{*}{$3046,2 \div 3048,2$} & $\mathrm{C} 1$ & 24,60 & 49,80 & 39,281 & 1,583 & 0,305 \\
\hline & & & & $\mathrm{C} 2$ & 24,52 & 47,60 & 53,794 & 1,992 & 0,293 \\
\hline & & - & - & $\begin{array}{l}\text { Mean } \\
\text { value }\end{array}$ & - & - & 48,34 & 1,923 & 0,220 \\
\hline
\end{tabular}

Table 3 Results of uniaxial compressive tests on rock specimens

\subsection{Determination of parameters by physical tests}

In this study, a well drilled by Sinopec Corp. in Luojia area of Shengli Oilfield is considered. The strata in the well region from top to bottom include: Pingyuan Group, Minghuazhen, Guantao Group, Dongying Group, Shahejia Group (from Shahejie Section One to Shahejie Section Four). The total well depth is $3390 \mathrm{~m}$, and the depth below the technical casing is $2907,68 \mathrm{~m}$. The well section has a diameter of $311,10 \mathrm{~mm}$ and a length of 2910 $\mathrm{m}$. In order to overcome the challenges brought by large stratum dipping angle, tilting strata and multiple interbed, the techniques, such as vibration reduction and pressurization, and optimized drill bits, were adopted to improve the drilling speed at large well sections. The records at that area indicate that high technical indicators have ever been achieved in similar fields. After the third spud, $200 \mathrm{~m}$ long continuous sealed core was drilled in corporation with Drilling Technology Research Institute. In spite of the lack of knowledge on strata and lithology, large depth of coring location, hard and compact rock, poor drillability and water inflow, 229,75 m core was successfully recovered, with the recovery rate being $96 \%$. The recovered core can be used to better understand gas storage in the shale gas reservoir at the Lower Shahejie Section Three of the Luojia area.

The mechanical tests on the rock specimens collected from the shale gas reservoir bed and relevant physical model tests on fracture initiation and propagation serve as the basis for the following numerical analysis. Tests on the permeability of the propped fractures were also conducted and the relevant results are listed in Tab. 1. The testing results on the Kaiser effect of the rock specimens under confining stresses are listed in Tab. 2. As can be seen from Tab. 2, the maximum horizontal stress is $55 \mathrm{MPa}$. The results of the uniaxial compressive tests of the rock specimens are listed in Tab. 3 .

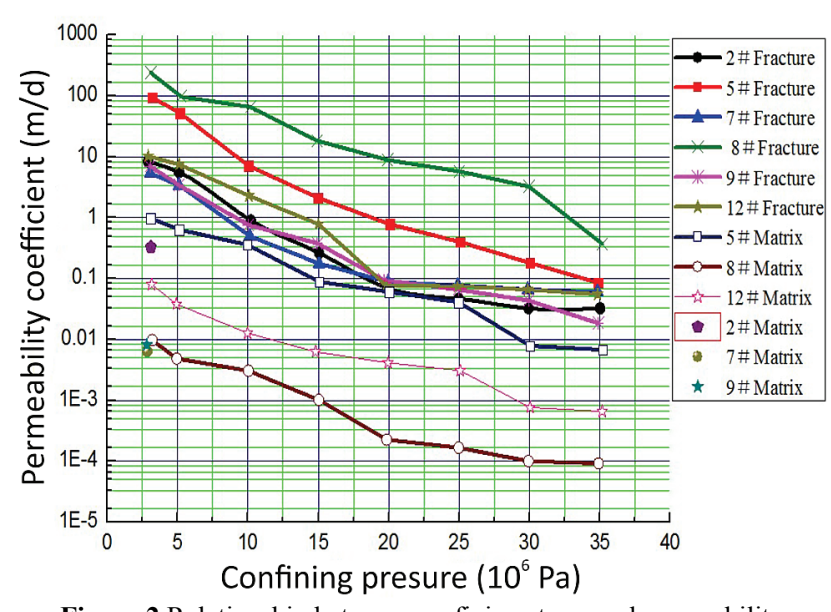

Figure 2 Relationship between confining stress and permeability

The testing results indicate that the matrix permeability of shale specimens varies in a wide range. As shown in Fig. 2, under a confining stress of $3 \mathrm{MPa}$, the maximum matrix permeability is $0,9 \mathrm{~m} / \mathrm{d}$, while the minimum is only $0,0051 \mathrm{~m} / \mathrm{d}$. Meanwhile, the matrix permeability of the shale is significantly affected by the confining stresses. The matrix permeability is increased by about $50 \%$ in average with an increment of $5 \mathrm{MPa}$ for the confining stress. The analysis results reveal that the difference can be attributed to sedimentary stratification. The effect of the confining stress on the matrix 
permeability is less significant if less sedimentary stratifications are present. If there are a number of sedimentary beds, the degree of the strata closure increases, leading to a significant reduction of the matrix permeability. In this study, the porosity of the shale specimen is very low under atmospheric pressure, roughly between $2 \div 5 \%$. In order to investigate the enhancement effect of unfilled fracture on the permeability of shale, in situ permeability tests were carried out after artificial fractures were closed.

As can be seen from the testing results, although some unfilled or dislocated fractures were closed, the systematic permeability of propped fractures was enhanced substantially. The matrix permeability was increased by $1 \div 4$ order of magnitude, and, in average, 3 order of magnitude. Therefore, hydraulic fracturing is worthy of being performed in that area for more efficient exploitation of the shale gas reservoir. The experimental data indicated that the permeability was increased by about 3 order of magnitude even if the fractures were unfilled, which is significant for the efficient exploitation of shale gas in that area. Based on the above physical testing results, the physical and mechanical parameters of the shale are summarized in Tab. 4.

Table 4 Parameters of the various layers of the horizontal well for the numerical modelling

\begin{tabular}{|c|c|c|c|c|}
\hline Mechanics and control parameters & Calcite $(70 \%)$ & Quartz (10\%) & Clay $(20 \%)$ & Overall \\
\hline Homogeneous degree $m$ & 2 & 2 & 2 & 2 \\
\hline Average elastic modulus $E_{0}\left(10^{9} \mathrm{~Pa}\right)$ & 33,9 & 56,5 & 11,3 & 33 \\
\hline Average compressive strength $\sigma_{0}\left(10^{9} \mathrm{~Pa}\right)$ & 1440 & 2400 & 480 & 220 \\
\hline Friction angle $\varphi\left(^{\circ}\right)$ & 45 & 45 & 45 & 45 \\
\hline Ratio of compressive strength and tensile strength $C / T$ & 15 & 15 & 15 & 15 \\
\hline Poisson's ratio $\mu$ & 0,26 & 0,26 & 0,26 & 0,26 \\
\hline Cohesion $\left(10^{9} \mathrm{~Pa}\right)$ & 2,54 & 2,54 & 2,54 & 2,54 \\
\hline Residual strength coefficient $\boldsymbol{\xi}$ & 0,1 & 0,1 & 0,1 & 0,1 \\
\hline Permeability $k(\mathrm{~m} / \mathrm{d})$ & $0,01 \div 1$ & $0,01 \div 1$ & $0,01 \div 1$ & $0,01 \div 1$ \\
\hline Permeability coefficient $K(\mathrm{~m} / \mathrm{d})$ & $8,64 \times 10^{-5}$ & $4,32 \times 10^{-5}$ & $4,32 \times 10^{-4}$ & $0,864 \times 10^{-3}$ \\
\hline
\end{tabular}

3 Effect of the ratio between vertical stress and maximum horizontal stress on the initiation and propagation of hydraulic fractures

Geostresses are the fundamental data for the development scheme of oilfield, the analysis of the propagation law of hydraulic fractures, and the prediction of stratum breakdown and fracturing stress. The differences between the physical and mechanical properties of various rock types in or between strata and these between the pore water pressures in the strata may lead to heterogeneous geostress distribution in or between strata. Moreover, the geostress plays a significant role in determining the hydraulic fracture initiation pressure, fracture initiation location, fracture propagation, and fracture pattern. Thus, the geostress is an important factor for fracture propagation during hydraulic fracturing. In this section, the effect of the difference between the vertical stress and the maximum horizontal stress on the propagation mechanism and law of hydraulic fractures will be discussed.

\subsection{Numerical models}

In this section, the seepage module of the realistic failure process analysis software (RFPA-FLOW) is adopted to simulate the effect of the difference between the vertical stress and the maximum horizontal stress on the initiation and propagation of hydraulic fractures. A two-dimensional rectangular model was built as shown in Fig. 3. The model has a dimension of $1200 \times 1200 \mathrm{~mm}$ and consists of $600 \times 600=360000$ elements. The loading condition is shown in Fig. 4. The model boundaries are impervious. A well with a diameter of 139 $\mathrm{mm}$ is created in the centre of the model. To model hydraulic fracturing, a gradually increasing hydraulic pressure $P_{f}$ is applied in the wellbore. The initial hydraulic pressure is $23 \mathrm{MPa}$ and the hydraulic pressure is increased with an increment of $1 \mathrm{MPa}$ per step until fractures are initiated and propagate leading to the specimen failure. A steady-state seepage field is assumed throughout the simulation. In order to investigate the effect of the difference between the vertical stress and the maximum horizontal stress on hydraulic fracture propagation, various combinations of the vertical stress and the maximum horizontal principal stress are selected, as shown in Tab. 5. The ratio of the vertical stress and maximum horizontal principal stress is defined as $\lambda$. Six modelling schemes are designed, in which the vertical stress remains unchanged (constant $\sigma_{\mathrm{V}}$ ) and the maximum horizontal principal stress is increased gradually (increasing $\sigma_{\mathrm{H}}$ ).

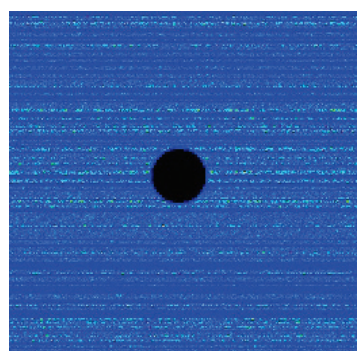

Figure 3 Numerical model for the stratified rock mass with a horizontal well

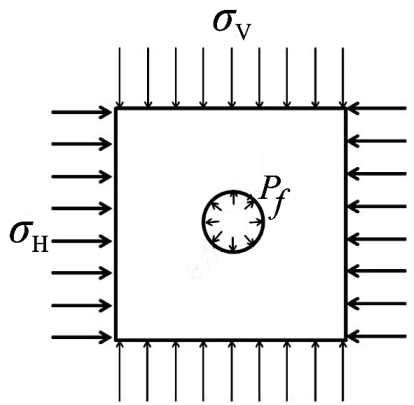

Figure 4 Schematic sketch of the loading conditions for the numerical model 
Table 5 Schemes of numerical tests

\begin{tabular}{|c|c|c|c|c|c|c|}
\hline Scheme & 1 & 2 & 3 & 4 & 5 & 6 \\
\hline$\sigma_{\mathrm{V}}\left(10^{6} \mathrm{~Pa}\right)$ & 61 & 61 & 61 & 61 & 61 & 61 \\
\hline$\sigma_{\mathrm{H}}\left(10^{6} \mathrm{~Pa}\right)$ & 61 & 55 & 51 & 47 & 41 & 31 \\
\hline Stress ratio, $\lambda$ & 1 & 1,1 & 1,2 & 1,3 & 1,5 & 2 \\
\hline
\end{tabular}

The fundamental mechanical parameters of the rock material, such as elastic modulus, Poisson's ratio, compressive to tensile strength ratio and friction angle, are taken from Tab. 4. The homogeneity index of the model is assumed as 2 so as to reflect the mesoscopic heterogeneity of the rock material. The strength, elastic modulus, Poisson's ratio and other parameters are assumed to satisfy the Weibull distribution aforementioned.

\subsection{Modelling results and analyses}

(1) Scheme $2\left(\sigma_{\mathrm{V}}=61 \mathrm{MPa}, \sigma_{\mathrm{H}}=55 \mathrm{MPa}, \lambda=1,1\right)$

Figs. 5, 6 and 7 present the distribution of the modelled minimum principal stress, pore water pressure, and acoustic emission, respectively, in the rock with the in-situ stresses of $\sigma_{\mathrm{V}}=61 \mathrm{MPa}$ and $\sigma_{\mathrm{H}}=55 \mathrm{MPa}$ as the hydraulic pressure in the well increases. According to the numerical simulation, the rock fracture process during the hydraulic fracturing can be divided into three stages, i.e., pre-fracturing, microfracturing and fracturing stages.

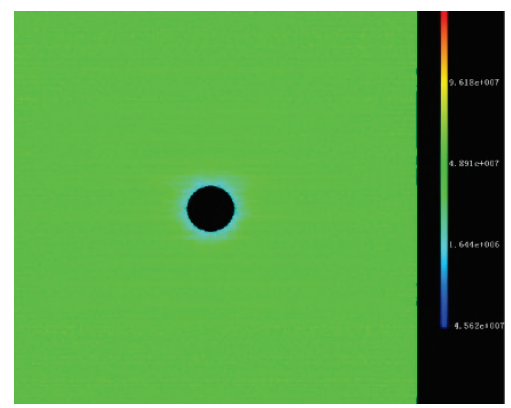

(a) Step 1

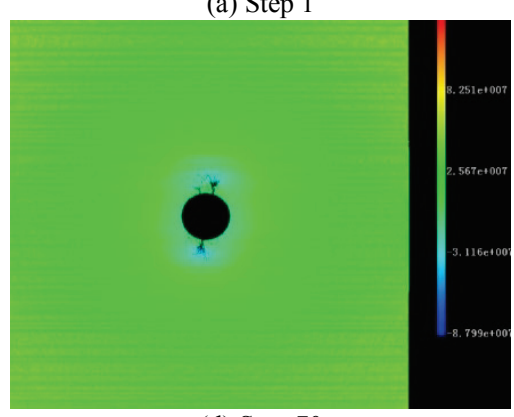

(d) Step 70

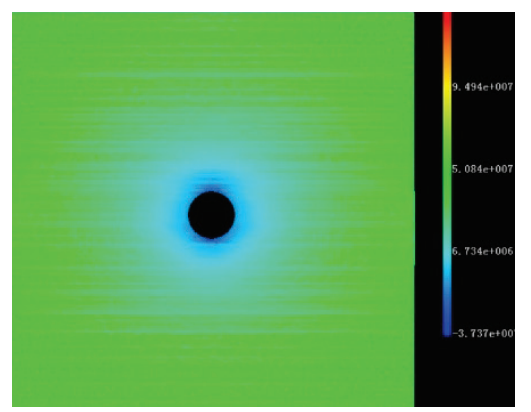

(b) Step 65

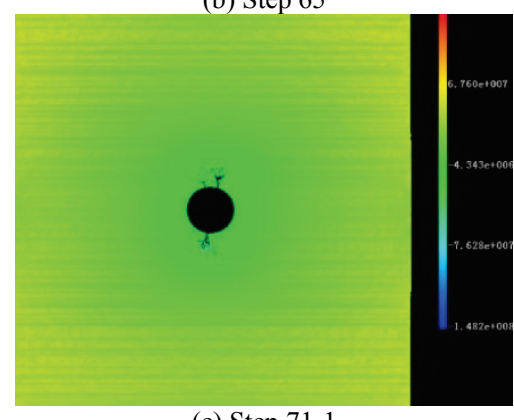

(e) Step 71-1

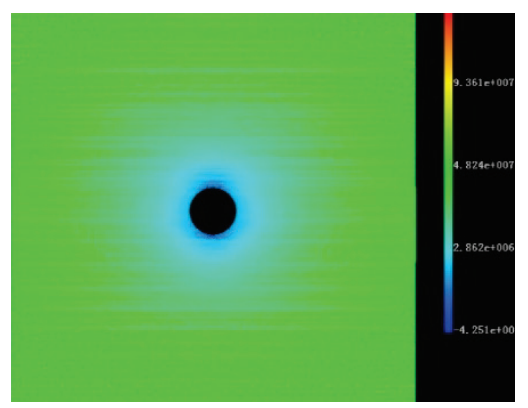

(c) Step 66

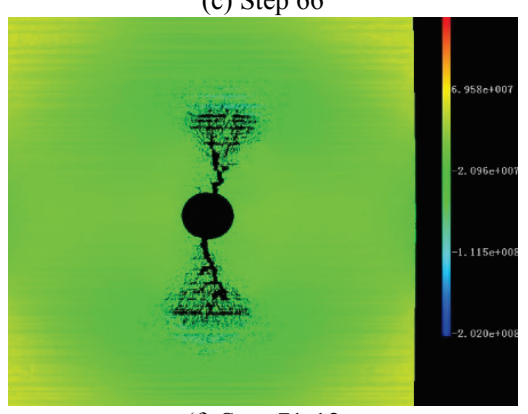

(f) Step 71-12

Figure 5 Distribution of minimum principal stress for Scheme $2(\lambda=1,1$, unit: $\mathrm{Pa})$

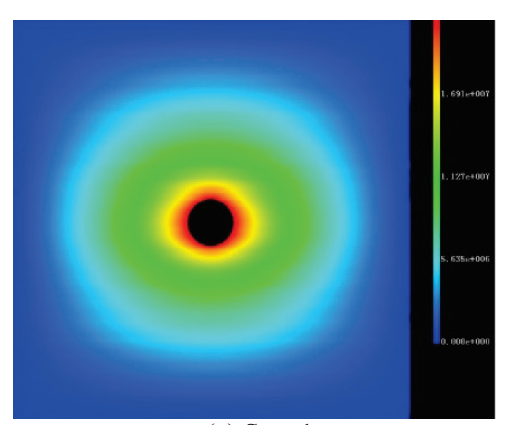

(a) Step 1

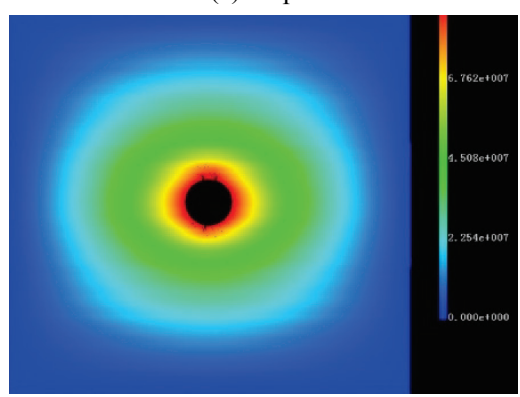

(d) Step 70

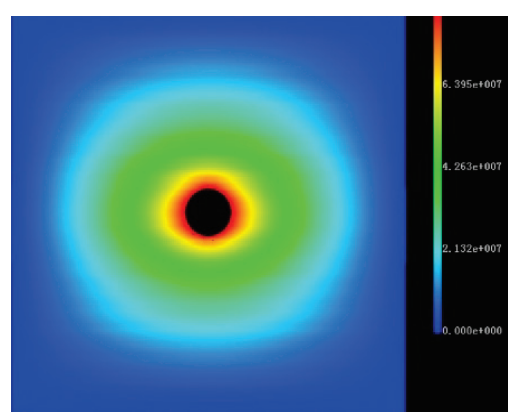

(b) Step 65

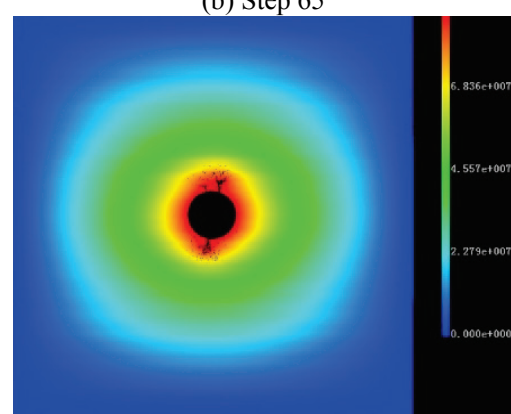

(e) Step 71-1

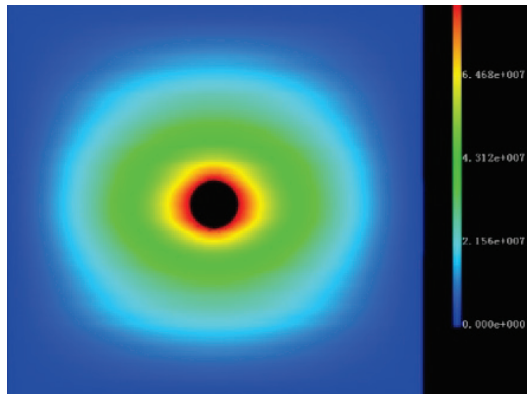

(c) Step 66

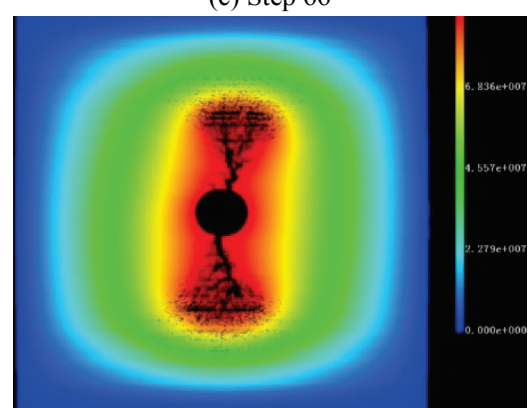

(f) Step 71-12

Figure 6 Distribution of pore water pressure for Scheme $2(\lambda=1,1$, unit: Pa) 


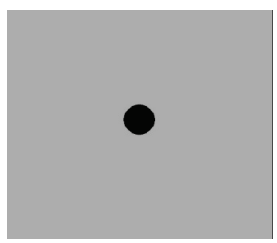

(a) Step 1

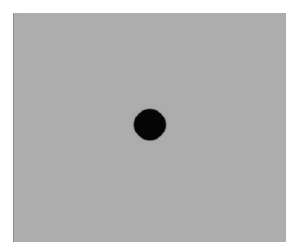

(b) Step 65

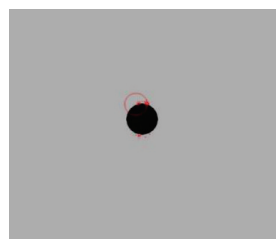

(c) Step 66

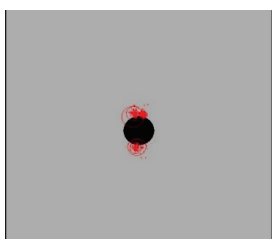

(d) Step 70

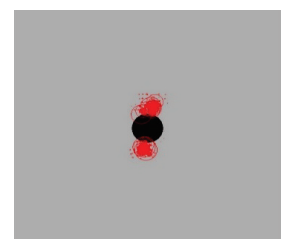

(e) Step 71-1

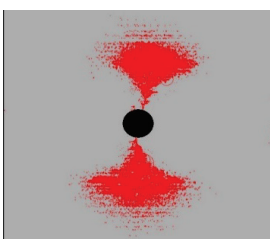

(f) Step 71-12

Figure 7 Plot of acoustic emissions for Scheme $2(\lambda=1,1)$

The pre-fracturing stage includes Step $1 \div$ Step 65 , in which the hydraulic pressure increases from $23 \mathrm{MPa}$ to 85 $\mathrm{MPa}$. During this stage, the specimen remains elastic and no element damage or failure occurs in the model. However, the stress continuously accumulates and concentrates in this stage, especially at the upper and lower boundaries of the well. Since the horizontal stratification is considered, stratified distribution of high stresses can be observed in the rock surrounding the well. The pore water pressure is distributed symmetrically in an elliptical shape with its centre at the centre of the well (Figs. 6a and 6b). The pore water pressure decreases exponentially from the well wall to the model boundary. Almost no acoustic emissions are recorded in Figs. 7a and $7 \mathrm{~b}$, which is consistent with the result obtained by laboratory tests.

The fracture initiation and propagation stage includes Step $66 \div$ Step 70, in which the hydraulic pressure is between $86 \mathrm{MPa}$ and $90 \mathrm{MPa}$. In this stage, with the further increase of the hydraulic pressure in the well, high stresses are accumulated at the well wall to a certain extent. At some locations with low strengths or high stresses, the tensile strength of the rock medium is satisfied leading to the occurrence of elemental damage. The red circles in Fig. 7c represent tensile stress - induced acoustic emissions, indicating that the failure mode is dominantly tensile failure. In Fig. 7d, a few white circles appear, too, showing that the acoustic emissions are caused by the elemental shear damages induced by shear stresses. It can be seen from Fig. 7, initially, the damaged elements are scattered. With increasing number of the damaged elements, these elements gradually cluster and microfractures are initiated. With further increasing of the hydraulic pressure, the microfractures propagate approximately along the vertical direction. It is also noticed that sporadic microfractures, which are not connected to the main fracture, appear near the fracture tip. The fracturing and failure stage includes Step 71, in which the hydraulic pressure reaches $91 \mathrm{MPa}$. As the hydraulic pressure keeps increasing, the microfractures coalesce to form a main fracture, which propagates in non-linear paths. It is noted that the fractures are curved or branched at some locations. Moreover, multi-layered fractures also occur, which is mainly caused by dominant tensile failures due to the effect of stratification. The formed macroscopic fracture propagates approximately in the vertical direction. With increasing number of the damaged elements in the vicinity of the formed macroscopic fracture, the tip of the fracture moves forward and the fluid with the high pressure flows into the fracture tip leading to high stresses there. Thus, the high stress zone is shifted to the crack tip and the high stress there becomes the driving force for further fracturing. As can be seen from Figs. 5e and 5f, the size, length and propagation direction of the fractures formed around the upper and lower boundaries of the well are not exactly the same, which is caused by the heterogeneity of the rock material.

Table 6 Final fracture pattern for various stress combinations (plots of pore water pressure and acoustic emission)

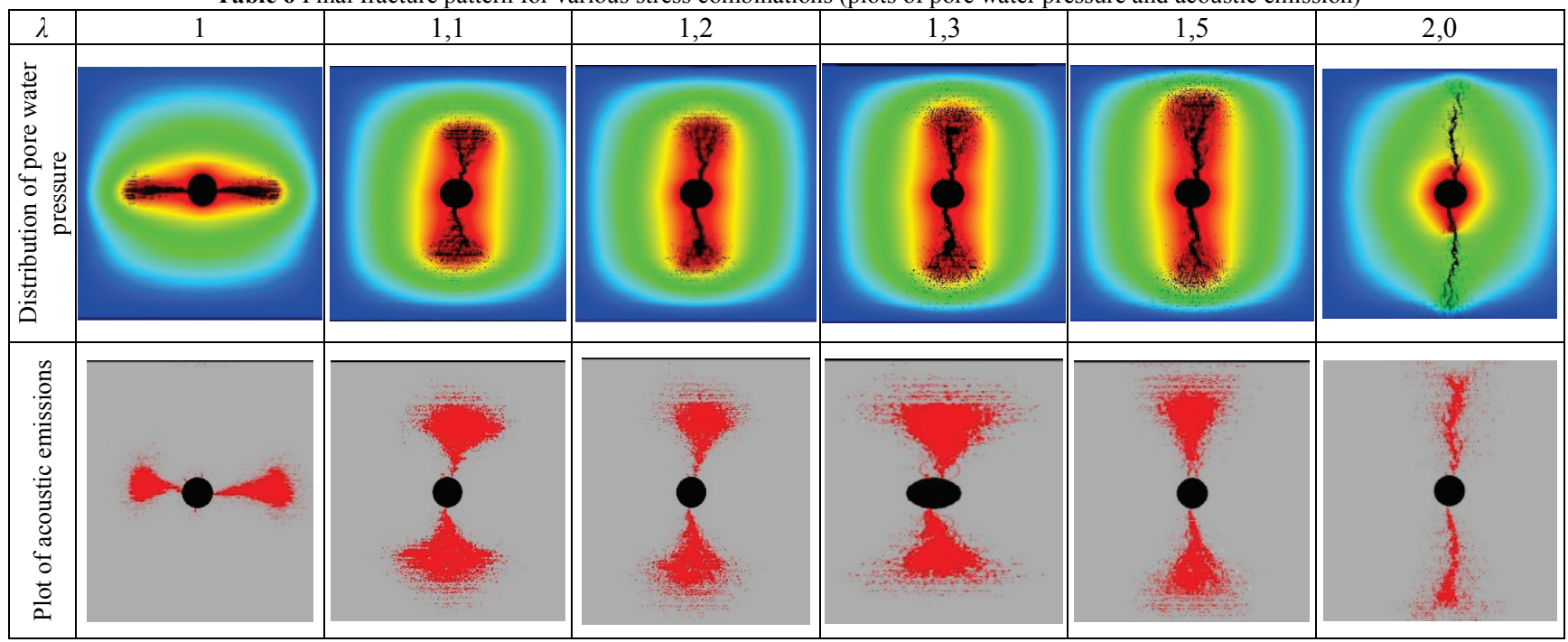

The final fracture pattern is basically an approximately symmetrical double-wing crack. From the acoustic emissions in Figs. 7e and 7f, it can be seen that the main failure mode is tensile failure, which is indicated by the red color, and the final fracture pattern is fan- shaped. The simulation results well explain why tensile failure is dominant during hydraulic fracturing in stratified shale. As long as the hydraulic pressure is high enough, the rock at very far distance can be fractured. However, given that the ratio of vertical stress and 
maximum horizontal principal stress is 1,1 , which is relatively small, a large area of microfractures can be formed instead of narrow and long hydraulic fractures, which is usually accompanied with the higher stress ratio.

As can be seen from the numerical simulation above, the rock deformation and failure process under hydraulic fracturing is a gradual deterioration process. With increasing hydraulic pressure in the well, microfractures or micro-holes have been formed in most hydraulically fractured rock mass before the occurrence of macroscopic fracture. Under the effect of various external factors, the microfractures and micro-holes are continuously initiated, propagate, coalesce and connect with each other. The physical-mechanical properties of the hydraulically fractured rock mass are deteriorated. As a result, the strength, stiffness and toughness of the rock mass are degraded. This process is called the damage process of the rock mass under hydraulic fracturing. During the entire process, due to the existence and evolution of the rock mass damage, the hydraulically fractured rock masses become further heterogeneous and discontinuous. Thus, the hydraulic fracturing process is in fact a process from initiation, propagation and coalescence of microfractures to formation of macrofractures and a process of increasing rock mass heterogeneity and discontinuity.

\section{(2) Other modelling schemes}

Tab. 6 summarizes the final fracture patterns and the corresponding acoustic emissions of the rock mass under different stress combinations during hydraulic fracturing. As can be seen from Tab. 6, only when the ratio between the vertical stress and the maximum horizontal principal stress is 1, the hydraulic fractures develop along the horizontal direction.

The fracture propagation direction is perpendicular to the horizontal stratifications in all other cases, i.e., along the direction of the vertical stress but the fracture pattern and length are different for different stress combinations, which are discussed in the following paragraphs.

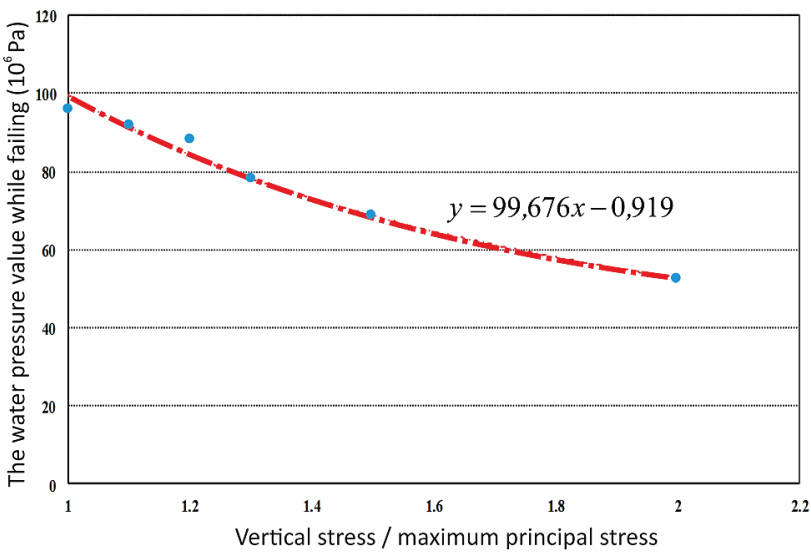

Figure 8 Relationship between the break-down hydraulic pressure and the in-situ stress ratio

1) When the confining stresses are high, failure occurs suddenly in the rock mass without the formation of large damaged area and with few acoustic emissions after the hydraulic pressure reaches a certain value.

2) Branched fractures are likely to form in stratified rock masses under hydraulic fracturing. The branch fractures occur at a distance of approximately 5 times of the perforation length.

3) When the ratio between the vertical stress and maximum horizontal principal stress is 1 , the effect of the stratification is most obvious and the hydraulic fractures propagate along the horizontal stratification direction. When the ratio is between 1 and 1,5 , the hydraulic fractures propagate perpendicularly to the stratification direction. However, the fracture propagation is affected by the stratification and more branch fractures are likely to occur along the stratification. When the ratio is greater than 1,5, the hydraulic fractures are less affected by the stratifications and less branch fractures are formed compared with those in the case that the ratio is between 1 and 1,5. Moreover, it is found that longer hydraulic fractures are formed even under lower hydraulic pressures when the ratio becomes bigger.

4) Fig. 8 depicts the relationship between the breakdown pressure, i.e. the hydraulic pressure when failures occur, and between the vertical stress and the maximum horizontal principal stress. It can be seen from Fig. 8 that the breakdown pressure decreases non-linearly with the ratio increasing. The break-down pressure is 96 $\mathrm{MPa}$ when the ratio is 1 , which is about twice of that (52 $\mathrm{MPa}$ ) when the ratio is 2 .

\section{Effect of the perforation angle on the initiation and propagation of hydraulic pressures}

At present, almost all wells are completed by perforation. Therefore, hydraulic fracturing is usually performed in the perforated well. The perforation is a channel between the well and rock strata. Fluid is pumped into the rock strata through the perforations. Therefore, the parameters of the perforations inevitably affect the hydraulic fracturing process. Proper parameters of the perforations can be determined based on the previous studies by experts and the analyses by site engineers, so as to reduce the fracture initiation pressure, reduce the degree of fracture distortion and avoid multiple fractures. The auxiliary directional hydraulic perforation technique has been successfully applied in oilfields worldwide. However, it has seldom been reported how to reduce the fracturing pressure and enhance the fracturing efficiency by adjusting the perforation angle.

In this section, a series of numerical simulations is conducted to study how the perforation parameters affect the hydraulic fracturing in wellbores completed by perforation and how the perforation orientation influences the hydraulic fracture initiation and propagation. Based on the numerical simulation results, the effect of the directional perforation angle on the fracture initiation, propagation and pattern is discussed.

\subsection{Numerical models}

In this section, a two-dimensional rectangular model is designed to simulate the hydraulic fracturing in a stratified rock mass medium through a horizontal well with different perforation angles, as shown in Fig. 9. The model size is $1200 \times 1200 \mathrm{~mm}$, consisting of $600 \times 600=$ 360000 elements. A wellbore is created in the model centre. An increasing hydraulic pressure $P_{f}$ is applied in 
the wellbore. The four boundaries of the model are impervious. The initial hydraulic pressure of the wellbore is set as $23 \mathrm{MPa}$, which is then increased by $1 \mathrm{MPa}$ per step until the fractures propagate and the rock mass medium fails. Steady-state seepage is assumed again throughout the simulation. In the numerical simulation model, the angle between the perforation direction and the vertical principal stress direction is $\alpha$, and the perforation length is $20 \mathrm{~mm}$. The physical-mechanical parameters of the rock material, including elastic modulus, Poisson's ratio, compressive to tensile strength ratio and friction angle, are listed in Tab. 4.

Table 7 Final fracture patterns in the stratified model $\left(\sigma_{\mathrm{V}}=61 \mathrm{MPa}\right.$ and $\left.\sigma_{\mathrm{H}}=55 \mathrm{MPa}\right)$ with various perforation angles

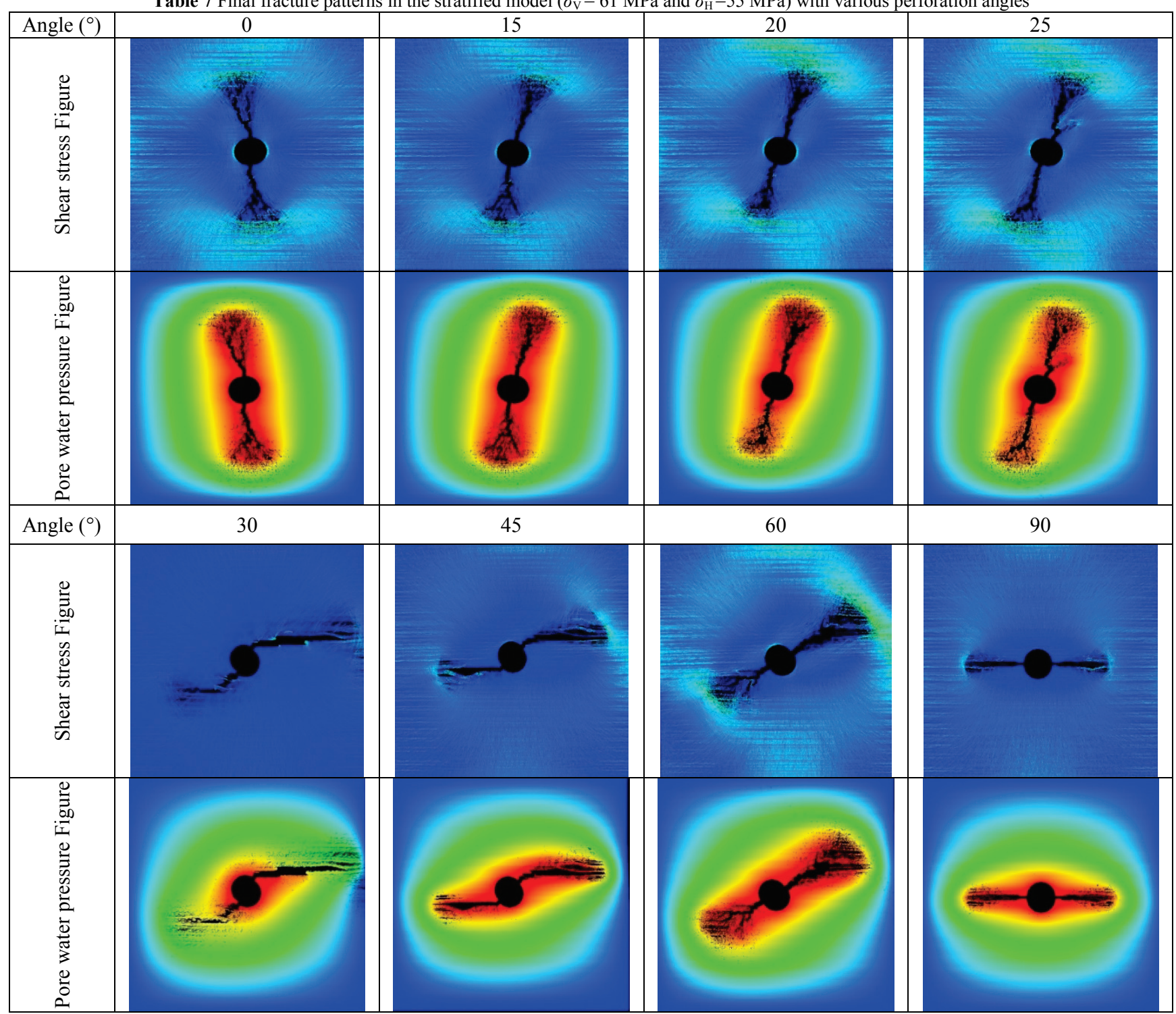

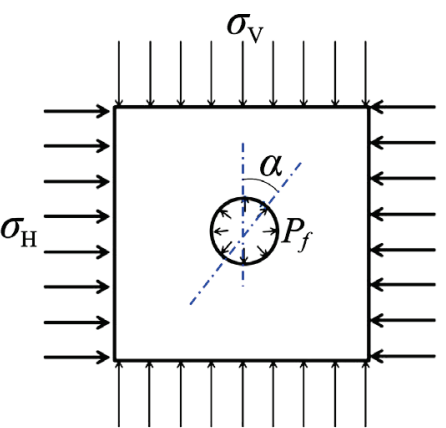

Figure 9 Schematic sketch of the numerical model

The homogeneity index is assumed to be 2 in order to reflect the mesoscopic heterogeneity of the rock material. The strength, elastic modulus and Poisson's ratio are assumed to satisfy the Weibull distribution in Eq. (1). Five cases with the perforation angles of $90^{\circ}, 60^{\circ}, 45^{\circ}$, $30^{\circ}$ and $0^{\circ}$ are simulated to investigate the effect of the perforation angle on the hydraulic fracturing in the stratified rock mass with the in-situ stresses of $\sigma_{\mathrm{V}}=61$ $\mathrm{MPa}$ and $\sigma_{\mathrm{H}}=55 \mathrm{MPa}$.

\subsection{Modelling results and analyses}

Tab. 7 summarizes the final fracture patterns caused by the hydraulic fracturing in the stratified models under the in-situ stresses of $\left(\sigma_{\mathrm{V}}=61 \mathrm{MPa}\right.$ and $\left.\sigma_{\mathrm{H}}=55 \mathrm{MPa}\right)$ for the five cases. It can be seen from Tab. 7, for the stratified rock mass under such stress combination, if the perforation angle is greater than $30^{\circ}$, the hydraulic fractures are mainly affected by the stratifications. Hydraulic fractures are initiated at the tips of the perforation, then turn to the nearest stratification and finally propagate along the horizontal stratification. 
Meanwhile, multiple parallel fractures are formed at the tips of the hydraulic fractures due to the stress concentration at the tips of the fractures. If the perforation angle is less than $30^{\circ}$, the hydraulic fractures are still initiated at the tips of the perforation but more branched fractures occur. Finally, the hydraulic fractures propagate approximately in the vertical direction.

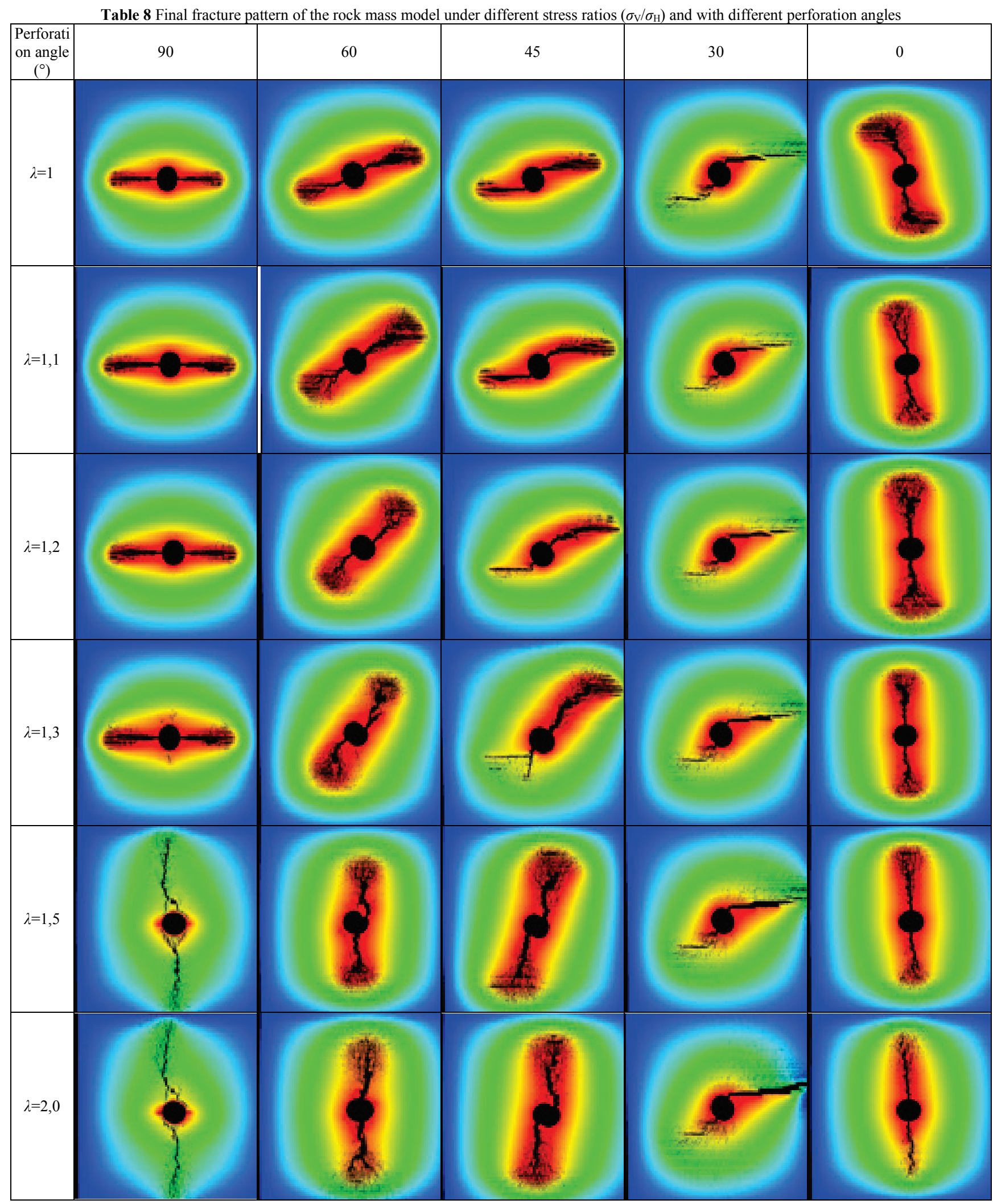

Besides studying the effect of the perforation angle on the hydraulic fracturing, the stress ratios $\left(\sigma_{\mathrm{V}} / \sigma_{\mathrm{H}}\right)$ are also varied to study their effect on the hydraulic fracturing in the stratified rock mass with a certain perforation angle.
The corresponding results are shown in Tab. 8 and Fig. 10 As shown in Fig. 10, under the same stress ratio, the hydraulic pressure required for the complete fracturing of the rock mass medium with a perforation angle of $30^{\circ}$ is 
higher than all other cases. If the perforation angle is the same, the hydraulic pressure required for the complete fracturing of the rock mass medium increases with the stress ratio decreasing. Moreover, from the analysis of the specific shape of the cracks, it can be concluded that, when the perforation direction is perpendicular to the vertical principal stress, no fractures are initiated from the perforation when the stress ratio between the vertical stress and the maximum horizontal principal stress is greater than 1,3. Instead, the fractures are initiated along the vertical direction. As a result, the casing is stripped away and a ring fracture surrounding the casing is formed. In all other cases, the hydraulic fractures are initiated from the tips of the perforation and propagate along the stratification direction. Compared with the case without the stratification, a higher stress difference is required to form the ring fractures due to the effect of the stratification. Due to the effects of the stratification and high stress difference, the hydraulic fractures are formed at the tips of the perforation and then turn to propagate along the stratification direction in the model with the perforation angles of $30^{\circ}$ and $45^{\circ}$. For the model with a perforation angle of $0^{\circ}$, the larger the ratio between the vertical stress and the maximum horizontal principal stress, the narrower and longer the hydraulic fractures and the less the branch. Moreover, the following summary can be made.

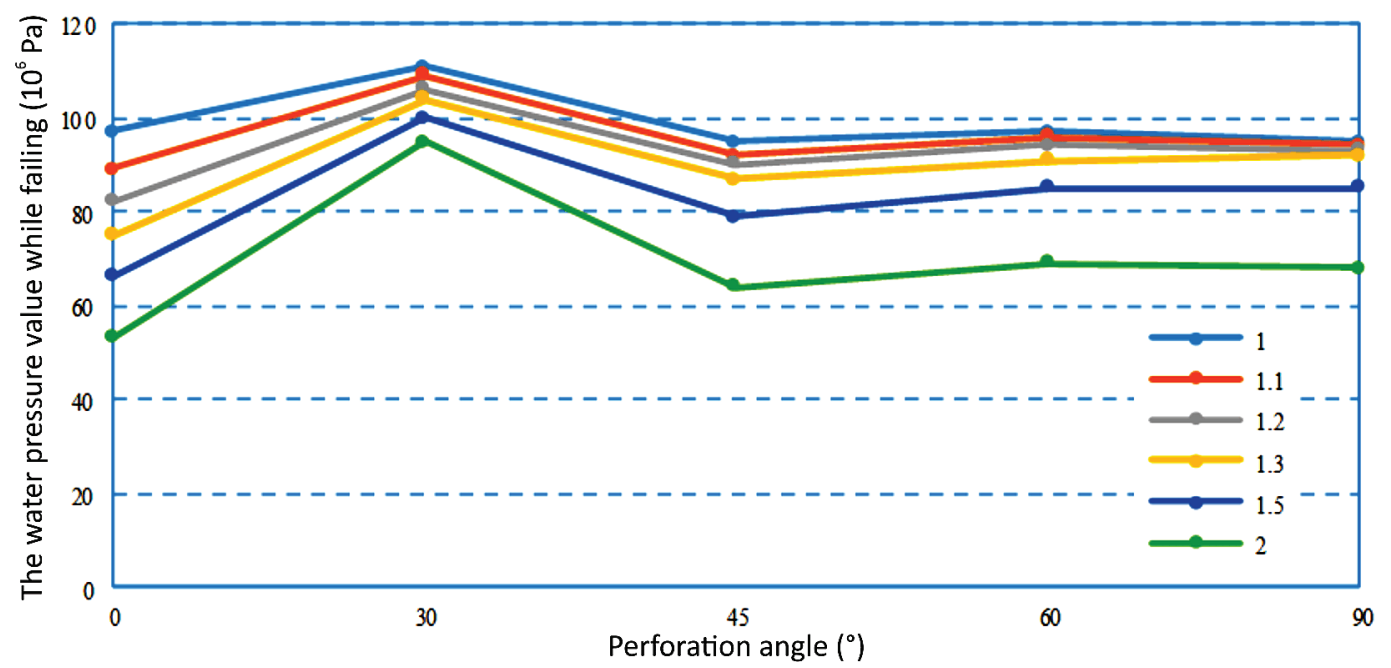

Figure 10 Plot of hydraulic pressures upon failure for different stress ratios and perforation angles

1) For the rock mass medium with the same perforation angle, the larger the stress ratio (i.e., lower maximum horizontal principal stress when the vertical stress remains constant), the lower the hydraulic pressure required for its complete hydraulic fracturing, i.e., the easier the hydraulic fracture formed.

2) For the rock mass medium under the same stress ratio, the hydraulic pressure required for its complete fracturing is higher in the case with a perforation angle of $30^{\circ}$ than all other cases.

3) When the perforation direction is perpendicular to the vertical principal stress, no fractures are initiated from the perforation if the stress ratio between the vertical stress and the maximum horizontal principal stress is greater than 1,3. Instead, the fractures are initiated in the vertical direction. As a result, the casing is stripped away and a ring fracture surrounding the casing is formed. In all other cases, the hydraulic fractures are initiated from the tips of the perforation and propagate along the stratification direction. Compared with the case without the stratification, a higher stress difference is required to form ring fractures due to the effect of the stratification.

4) Due to the effects of the stratification and high stress difference, the hydraulic fractures are formed at the tips of the perforation and then turn to propagate along the stratification direction in the rock mass model with the perforation angles of $30^{\circ}$ and $45^{\circ}$. For the model with a perforation angle of $0^{\circ}$, the larger the ratio between the vertical stress and the maximum horizontal principal stress, the narrower and longer the hydraulic fractures and the less the branch fractures. The smaller the stress ratio, the more pronounced the effect of the stratification, the more the branch fractures and the shorter the main fracture.

5) When the ratio between the vertical stress and the maximum horizontal principal stress is larger than 1,3 and the perforation angle is greater than $60^{\circ}$, the hydraulic fractures are completely controlled by the vertical stress.

\section{Conclusion}

A total of six different in-situ stress ratios and eight different perforation angles were considered for the hydraulic fracturing in the stratified rock mass. The obtained results from these various combinations indicate that, for the stratified rock mass with the same perforation angle, the larger the stress ratio (i.e., lower maximum horizontal principal stress when the vertical stress remains constant), the lower the hydraulic pressure required for its complete hydraulic fracturing, i.e. the easier the hydraulic fractures formed. Moreover, it is found that, for the stratified rock mass under the same stress ratio, the hydraulic fracturing pressure in the case of the horizontal well with a perforation angle of $30^{\circ}$ is higher than that in all other cases. Furthermore, it is noted that the effect of the stratification becomes weaker with the stress ratio increasing. 
Future research should be carried out to build threedimensional (3D) models for the hydraulic fracturing in the stratified rock mass using the horizontal wells since the fluid that flows along the third direction may play a very important role in the process of the hydraulic fracturing. It is expected that the $3 \mathrm{D}$ models should be more convincing than the two-dimensional ones in terms of simulating the hydraulic fracturing. Moreover, the forming process of the 3D fracture network during the hydraulic fracturing stimulation in the shale gas reservoir can be simulated using the $3 \mathrm{D}$ models. As a result, a better comparison between the numerical simulation and the monitoring data from practical projects can be carried out, which is of great directive significance to engineering practice.

\section{Acknowledgements}

This study was supported by the National Key Basic Research Development Plan (973) (No. 2011CB013500), the Science Fund for Creative Research Groups of the National Natural Science Foundation of China (Grant No. 51421064) and the Chinese National Natural Science Foundation (No. 41572249), which are greatly appreciated.

\section{References}

[1] Scott, K. Modern Shale Gas -Development in the United States: A Primer. // U. S. Department of Energy, Office of Fossil Energy, National Energy Technology Laboratory, 2002.

[2] Jiang, H. Y.; Song, X. M.; An, X. X. The review on world shale gas resources and exploration technology. // Natural Gas Technology. 2, 6(2008), pp. 26-30.

[3] Bai, Z. H.; Shi, B. H.; Zuo, X. M. The Study on Shale gas and its accumulation mechanism. // Natural Gas and Oil. 29, 3(2011), pp. 54-57

[4] Jia, L. C.; Chen, M.; Jin, Y. Progress of hydraulic fracturing fracture monitoring technology for shale gas wells in foreign countries. // Natural Gas and Oil. 30, 1(2012), pp. 44-47.

[5] Hubbert, M. K.; Willis, D. G. Mechanics of hydraulic fracturing. // Transaction of American Institute of Mining, Metallurgical, and Petroleum Engineers. 1972, pp.239-257.

[6] Sun, K. M.; Cui, H.; Lee, C. Q. Numerical simulation of propagation of oriented crack prefabricated in hydraulic fracturing. // Journal of Liaoning Technical University. 25, 2(2006), pp. 176-179.

[7] Zhao, J. J.; Ren, L.; Hu, Y. Q. Controlling factors of hydraulic fractures extending into network in shale formations. // Journal of Southwest Petroleum University (Science \& Technology Edition. 35, 1(2013), pp. 1-9.

[8] Chen, M.; Pang, F.; Jin, Y. Experiments and analysis on hydraulic fracturing by a large-size triaxial simulator. // Chinese Journal of Rock Mechanics and Engineering. 19, (2000), pp. 868-872.

[9] Warpinski, N. R; Teufel, L. W. Influence of geologic discontinuities on hydraulic fracture propagation. //Journal of Petroleum Technology. 39, 2(1987), pp. 209-220. DOI: 10.2118/13224-PA

[10] Warpinski, N. R. Hydraulic fracturing in tight, fissured Media. // Journal of Petroleum Technology. 43, 2(1991), pp. 146-209. DOI: 10.2118/20154-PA

[11] Warpinski, N. R.; Lorenz, J. C.; Branagan, P.T. et al. Examination of a cored hydraulic fracture in a deep gas well. // Society of Petroleum Engineers Production \& Facilities. 8, 3(1993), pp. 150-158. DOI: 10.2118/22876-PA

[12] Blanton, T. L. An experimental study of interaction between hydraulically induced and pre-existing fractures. // Society of Petroleum Engineers Unconventional Gas Recovery Symposium / Pittsburgh, 1982, pp. 559-571.

[13] Blanton, T. L. Propagation of hydraulically and dynamically induced fractures in naturally fractured reservoirs. // Society of Petroleum Engineers Unconventional Gas Technology Symposium / Louisville, 1986, pp. 613-627.

[14] Chen, M.; Pang, F.; Jin, Y. Experiments and analysis on hydraulic fracturing by a large size triaxial simulation. // Chinese Journal of Rock Mechanics and Engineering. 19(Sup.) (2000), pp. 868-872.

[15] Zhou, J.; Chen, M.; Jin, Y. et al. Experimental study on propagation mechanism of hydraulic fracture in naturally fractured reservoir. // Acta Petrolei Sinica. 5, 28(2007), pp. 109-113.

[16] Zhou, J.; Chen, M.; Jin, Y. et al. Experiment of propagation mechanism of hydraulic fracture in multi-fracture reservoir. // Journal of China University of Petroleum: Natural Science Edition. 4, 32(2008), pp. 51-54.

[17] Chen, M.; Zhou, J.; Jin, Y. et al. Experimental study on fracturing features in naturally fractured reservoir. // Acta Petrolei Sinica, 3, 29(2008), pp. 431-434.

[18] Mahrer, K. D. A review and perspective on far-field hydraulic fracture geometry studies. // Journal of Petroleum Science and Engineering. 24, 1(1999), pp. 13-28. DOl: 10.1016/S0920-4105(99)00020-0

[19] Beugelsdijk, L. J. L.; de, Pater, C. J.; Sato, K. Experimental hydraulic fracture propagation in multi-fractured medium. // Society of Petroleum Engineers Asia Pacific Conference on Integrated Modelling for Asset Management / Yokohama, 2000, pp. 101-108.

[20] Fisher, M. K.; Wright, C. A.; Davidson, B. M. et al. Integrating fracture mapping technologies to optimize stimulations in the Barnett shale. // Society of Petroleum Engineers Annual Technical Conference and Exhibition / San Antonio, 2002, pp. 230-236.

[21] Fisher, M. K.; Heinze, J. R.; Harris, C. D. et al. Optimizing horizontal completion techniques in the Barnett shale using microseismic fracture mapping. // Society of Petroleum Engineers Annual Technical Conference and Exhibition / Houston, 2004, pp.123-133.

[22] Maxwell, S. C.; Urbancic, T. I.; Zinno, R. Microseismic imaging of hydraulic fracture complexity in the Barnett shale. // Society of Petroleum Engineers Annual Technical Conference and Exhibition / San Antonio, 2002, pp. 25-33.

[23] Urbancic, T. I.; Maxwell, S. C. Microseismic imaging of fracture behavior in naturally fractured reservoirs. // SPE/ISRM Rock Mechanics Conference / Irving, 2002, pp. 152-158.

[24] Johannes, D. B; Lars, O. N. Process Simulation and Plant Layout of a Combined Cycle Gas Turbine for Offshore Oil and Gas Installations. // Journal of Power Technologies. 95, 1(2015), pp. 40-47.

[25] De Miguel, J. A.; Gutyrya, S. S.; Jomyak, Y. M. Stress in hollow axis with a surface crack under rotation and bending. // DYNA, 89, 1(2014), pp. 85-88.

\section{Authors' addresses}

Tianhui Ma, Ph.D. (Corresponding author)

State Key Laboratory of Coastal and Offshore Engineering, Dalian University of Technology

School of Civil Engineering, Dalian University of Technology

No. 2 Linggong Road, 116024 Dalian, P. R. China

E-mail: tianhuima@dlut.edu.cn 


\section{Quan-ao Wu, M.D Candidate}

School of Civil Engineering, Dalian University of Technology

No. 2 Linggong Road, 116024 Dalian, P. R. China

E-mail: quanaowu@foxmail.com

\section{Chun-an Tang, Ph.D., Professor}

School of Civil Engineering, Dalian University of Technology

No. 2 Linggong Road, 116024 Dalian, P. R. China

E-mail: tca@mail.neu.edu.cn

\section{Hongyuan Liu, Ph.D.}

School of Engineering and ICT, University of Tasmania, Hobart, TAS7001, Australia

E-mail: Hong.Liu@utas.edu.au 